\title{
Management and Science University BTESL Students' Perceptions towards Anxiety in Oral Presentation
}

\author{
${ }^{1, *}$ Mohammad A. Al-Saggaf \\ mohammad_ali@msu.edu.my \\ $\&,{ }^{2}$ Amira Aida Iman binti Azman \\ amiraaida.aai@gmail.com \\ 1,2, Management and Science University, Malaysia
}

Received: 02.01.2020 • Accepted: 01.03.2021 • Published: 31.03.2021 • Final Version: 31.03.2021

\begin{abstract}
Regardless of age, students often experience anxiety in oral presentations. This quantitative study investigates the perceptions of students towards anxiety in oral presentation in a tertiary educational context. It aims to examine students' perceptions of anxiety in oral presentations and the factors affecting anxiety in oral presentation. A total of three hundred and two students taking Bachelor in Teaching English as a Second Language (BTESL) in Management and Science University, Malaysia participated in this study by answering an adapted questionnaire with two sections: demographic and anxiety in oral presentation. The items under anxiety in oral presentation revealed students' perceptions towards anxiety in oral presentation and factors affecting anxiety in oral presentation. Collected data were analyzed through Statistical Package for Social Sciences (SPSS). Results showed that the respondents perceived anxiety in oral presentation to be negative. Moreover, there were six factors affecting anxiety in oral presentation which were preparation, number of presentations, teacher's feedback, audience's attention, selfconfidence and make mistakes. Thus, the results concluded that the students perceived anxiety in oral presentation to be negative and perceived that the major factor affecting their anxiety was preparation.
\end{abstract}

KEYWORDS: Anxiety; TESL; oral presentation perceptions; attention; feedback, selfconfidence.

\section{Introduction}

Oral presentations occur in most courses in tertiary education, especially ESL/EFL subjects. This type of assessment is essential when students need to communicate and systematically present their ideas and content, either individually or in groups. There are various benefits

\footnotetext{
*Corresponding Author.mohammad_ali@msu.edu.my
} 
of conducting oral presentations, such as students would gain more confidence, enhance soft skills, and prepare them for future presentations during work situations. However, students considered the academic oral activity as a situation that causes the highest anxiety (Woodrow, 2006; King, 2002, Woodrow \& Chapman, 2002). These feelings of anxiety can be translated through different physiological responsivities like disturbance of speech, silence periods, slow pace of speech, flushed face, and repeating gestures (Geer, 1966; Lewin, Jackson, \& McNeil, 1996). Hence, various studies were conducted to investigate students' causes of anxiety in oral presentations in recent years (Chen, 2015; Mak, 2011; Woodrom, 2006). This research briefly investigates the perceptions of students taking Bachelor in Teaching English as a Second Language in Management and Science University towards anxiety in oral presentation and factors affecting anxiety in oral presentation.

Most students experience stutter and sudden blank in oral presentations due to extreme nervousness or anxiety. Even with numerous practices, memorized or mastering the content, an individual could easily be distracted or disturbed due to internal or external factors. The first theory that provides insight on anxiety in foreign language was theory of foreign language anxiety by Horwitz, Horwitz and Cope's. Hence, Foreign Language Classroom Anxiety Scale (FLCAS) was introduced as anxiety level measurement to evaluate "communication apprehension, test anxiety and fear of negative evaluation." The FLCAS has helped many researchers to investigate the anxiety level and reasons of anxiety in their research. However, many studied language anxiety from various perspectives, ranging from anxiety level, factors of anxiety, and strategies to overcome anxiety, either in oral presentations, public speaking or any other academic presentations.

Students broadly execute oral presentations since middle school up until tertiary level of education. It is closely related to having good communication skills to ensure the message and content are delivered smoothly for the audience to receive and comprehend. Good communication skills, especially in English is essential because it is highly demanded in the current world (Richards, 2006; Yassin et al., 2019). However, most students' anxiety, regardless of age and gender regarding oral presentations is not understood by other people since anxiety is a phenomenon of abstract psychology (MacIntyre \& Gardner, 1989). This is considered a problem for both educators and students because students' academic performances would be negatively affected when they face anxiety during an oral presentation due to low self-esteem (McCroskey, 1977; Lederman, 1982), and educators would not be able to help in regards of their marks. In addition, (Woodrow, 2006; King, 2002, Woodrow \& Chapman, 2002) discovered academic oral presentation is the most engaged activity for university students, but it is also the most anxiety-provoking situation for them. Hence, many studies were conducted to determine causes affecting students' anxiety in oral presentations such as (Asif, 2017; Raja, 2017; Tulgar, 2018). However, this particular study provides a more detailed investigation on students of Bachelor in Teaching English as a Second Language (BTESL) in Management and Science University (MSU) regarding their perceptions towards anxiety in oral presentation and factors affecting anxiety in oral presentation.

This research is significant because oral presentations are often conducted in academic settings including real-life situations such as during interviews and work presentations. Students all around the world would need to experience this oral activity no matter the education level. Hence, there are two primary significances of this research. Firstly, to add 
more information towards previous research as the sample of this study varies from other studies that focus on one course, Bachelor in Teaching English as a Second Language in Management and Science University, Malaysia. Furthermore, this study is essential to provide useful information in the field of education and for educators regarding students' perceptions of anxiety and their possible causes of anxiety in oral presentation which could be understood, helped and reduced by both educators and students through effective solutions. For that purpose, the following research questions were created.

1. What are MSU BTESL students' perceptions towards anxiety in oral presentation?

2. What are MSU BTESL students' perceptions towards factors affecting anxiety in oral presentation?

\section{Literature Review}

\subsection{Perceptions towards anxiety in oral presentation}

Tian (2019) conducts a study on students from a Korean national university regarding their perceptions and factors affecting anxiety during classroom presentations through observation in the classroom, questionnaire, and interviews. The findings revealed that respondents have various anxiety levels, which is highest during presentations that they are not fully prepared for. The characteristics of anxiety such as subconscious behavior, quietness, speaking disruption and slow pace of articulation are also recognized. Furthermore, anxiety perceptions are assessed through ten items in the questionnaire, which revealed that respondents would feel immediately relaxed after they finish the presentation. Heart pounding represents a high anxiety level, and respondents still feel anxious during presentation even with full preparation. The study finds four main factors of anxiety during presentations which are pessimistic towards presentations, preparation period, language proficiency and peers giving negative feedback. However, there are minor factors such as making errors, audience's attention, and feedback from teachers. These factors and participants' perceptions of anxiety in presentations are confirmed based on conducted semi-structured interview.

Navaz and Banu (2019) examine students' experiences anxiety, factors contributing to language anxiety, and strategies to handle the anxiety. Findings reveal that students feel most anxious during oral activities such as test and presentations, and half of the respondents feel anxious "sometimes" in ESL classes. However, results show that respondents consider oral presentations and picture description activity as necessary, while storytelling and role-plays are the least favorable. The findings also reveal that respondents' anxiety behavior is as follows; freeze up, pounding and accelerated heartbeat, feeling of panic and discomfort in the seats, followed by minor manifestations such as shaking, sweating, stutter and headache. Factors contributing to students' anxiety are communication apprehension such as fearing of committing errors and negative feedback from lecturers, test anxiety and speaking English in classes. Finally, the strategies obtained from this study develop optimism, self-confidence, share the struggles of speaking with peers or lecturers and participate in more speaking activities to be able to overcome language anxiety. 
Miskam and Saidalvi (2019) examine the English language speaking anxiety level and the causes affecting it. The results show that most respondents experience moderate anxiety level, followed by high and low with an equal number. The respondents of high anxiety level reveal speaking anxiety causes such as communication apprehension, followed by the fear of negative feedback and test anxiety. Meanwhile, respondents of moderate anxiety level have similar sequences with high anxiety respondents except that the last two causes do not have similar means. In addition, respondents of low anxiety level reveal causes of anxiety in communication apprehension, test anxiety and fear of negative feedback. This research concludes that such causes negatively impact respondents' speaking performances.

Almira, Rachmawati and Faridah (2018) conduct a case study on 30 students' perceptions towards anxiety of speaking in oral presentation and strategies in managing anxiety. The study finds both male and female respondents experience anxiety during presentation due to individuality, peers, and teachers. Furthermore, the results reveal three main strategies that respondents can apply in managing their anxiety. Firstly, the students experienced a feeling of confidence and understanding the material. Secondly, the students created a cheerful surrounding and replied in jokes politely when receiving snarky comments. Finally, the students increased preparation period to understand the content and practice in front of mirror to achieve fluency, provide an interesting slideshow and maintain pace to ensure it is not too fast or too long during the presentation.

Khusnia (2016) examines the causes of speaking anxiety from the students' perspectives and factors that could reduce anxiety. The interview findings show major negative experiences by respondents with language class as it causes them to feel frustration and even anger. The study also reveals various causes of anxiety in speaking such as inability to comprehend classroom content, activities that require speaking, amendment of errors and being negatively compared to native speakers in class. The factor, correction of errors, reveals that when teachers pointed at their errors, they were confused. They were also frustrated when the teacher corrects them without allowing them to completely develop a response. Frequent interruptions from teachers to correct their speaking errors resulted in losing focus during speaking. Meanwhile, the study provides factors that could reduce students' anxiety, such as a sense of community among peers, positive classroom environment, and teacher's positive role. The findings related to previous studies prove that anxiety can impact students' language learning experience negatively.

\subsection{Factors affecting anxiety in oral presentation}

Alnahidh and Altalhab (2020) examine students' anxiety level and causes of FLSA in English classes. The findings reveal that respondents experience a moderate anxiety level in class which the authors believe it is considered alarming and needs to be overcome as it negatively affects students' speaking performance. Meanwhile, anxiety causes are the fear of errors, obligated involvement, insufficient practice, vocabulary, and grammar. However, there are also other causes of anxiety: fear of pronunciation, teachers' negative behavior and compulsory oral presentations. The study describes that respondents are afraid of mistakes as they want to maintain a positive image of themselves, resulting in hesitation and avoidance of speaking to steer clear from errors. It could also relate to teachers' ways of correcting students' errors, making them feel scared to speak as they fear being 
corrected. Furthermore, lack of preparation shows that respondents lack speaking practices, which makes them more anxious. Respondents' interviews also support the above causes of anxiety in speaking. Results show that oral presentation is the highest cause of anxiety for students. However, teachers with kind personalities, such as smiling and accepting errors, help students reduce anxiety. The study also provides several recommendations to reduce speaking anxiety, such as teachers respectfully correcting students, conducting presentations in small classes and providing relatable speaking topics for students.

Fadlan (2020) examines types of anxiety in foreign language and causes of anxiety in language during classroom presentation. The results reveal three types of anxiety; facilitative anxiety that motivates students to be more efficient; debilitative anxiety which is negative; and non-effecting anxiety that occurs when respondents experience low anxiety. Moreover, the factors of language anxiety are divided into internal and external factors. The factors are fear of mistakes, unpredictable questions, failure in examination, incapable of finding appropriate words to deliver content, low self-confidence and proficiency, lack of preparation and presentation experience, and poor pronunciation. The author mentions that graduate program students often face critical audience, making them more anxious in conducting errors in front of examining panel and peers. In conclusion, the author suggests that teachers be aware and understand the types of anxiety and acknowledge it in their students. This would help change the students' anxiety into something positive and motivate them to perform better in presentations.

$\mathrm{K}$ and Alamelu (2020) examine the causes of speaking anxiety and ways to overcome it. The results reveal two types of factors, external and internal. The former factors are language, grammar, pronunciation, and peers. The peer factor shows that respondents feel their peers will laugh at them, or their peers are better than them. Meanwhile, internal factors are stage fear, lack of confidence and shyness. Many respondents report they lack confidence, which authors believe low proficiency level and poor communication skills would result in lower confidence levels. This factor is categorized as an affective factor which is an internal factor that impacts students' performance results level to be low. The study also provides various strategies to improve speaking such as receiving encouragement from teachers, participating in seminars, practices to improve language skills or speak with siblings, in front of mirror or listen to others converse in English. The authors conclude that teachers should recognize students' needs and develop activities accordingly.

Soomro, Siming, Shah, Rajper, Naz and Channa (2019) investigate the causes of anxiety during English oral presentation through a questionnaire. The findings reveal two essential things, oral presentation is the most challenging skill for the respondents, and there are six main anxiety factors. The factors are arranged from the highest to lowest; nervous and stress, poor motivation and speaking skills, worry and anxiety, timidity and low self-esteem with similar frequency. Fear and anxiety are described as respondents unable to present information effectively and would be silent or mumble during the presentation. Hence, they feel worried and not relax, making them want to conclude the presentation the fastest they could. In addition, respondents describe low self-confidence as certain of their body parts are highly tense and occasionally become stiff. They believe their thoughts are mixed and disorganized and would often avoid presenting in front of peers. Respondents also avoid answering during presentation due to this factor. In conclusion, respondents' oral communication skills performances are generally affected, but oral presentation is the most affected. All of the above factors are given suggestions by authors to overcome it by 
teachers to provide sufficient practice, motivation, training, and awareness of the importance and knowledge regarding oral communication skills.

Anwari (2019) examines the factors and negative impacts of English language speaking anxiety. The results reveal factors such as fear of pronunciation mistakes, peers laughing at them speaking in English, and worrying about oral presentation. One of the factors, peers laugh at respondents speaking in English, occurs due to lack of motivation and peer anxiety from classmates, showing they do not know how to motivate and support one another. This finding is aligned with Rafada (2017) and Tsui (1996), which shows that this is one major factor affecting students' anxiety in speaking. Finally, the negative impacts of learners' anxiety are; it restricts their fluency in speaking, feels pressured during a presentation and reduces their confidence level and oral performance.

Tulgar (2018) examines factors of speaking anxiety and strategies to manage speaking anxiety. The results show factors such as fear of errors, evaluated negatively, sudden questions, comparing self with others and self-evaluation. This study reports respondents' experiences of fear of mistakes while using the target language for communication purposes. This finding is aligned with previous researches, Ozturk (2009), He (2013) and Yoshida (2013), which shows it is a factor that negatively influences students' speaking skills. Another factor, fear of negative evaluation, also relates with fear of making errors as respondents fear being assessed by native speakers due to speaking errors that show these factors trigger one another and vice versa. However, other context-specific factors include fear of communication with native speaker lecturers, local's accents, and differences in cultures. Finally, the findings provide coping strategies such as understanding that mistakes are common, acknowledging native speakers for enhancement of language and culture, being prepared, and do listening or watching activities.

Ka-kan-dee and Al-Shaibani (2018) examine students' level of anxiety and feelings during oral presentation using questionnaires and interviews. Findings show that most respondents have the highest level of anxiety during oral presentations and the interview reveals that most of them dislike oral presentations. This is because the respondents have low confidence and low presentation skill, which requires content memorization. The interviews reveal three significant anxiety causes students face during oral presentations: framework of presentation, individual and assessment characteristics. However, this study confirms the PET theory that views anxiety to have positive and negative effects on an individual's performance. The respondents experience high level of anxiety in oral presentations but it has pushed them to be well prepared for it.

\section{Materials and Methods}

\subsection{Research Design}

The researcher utilized a quantitative research method to investigate MSU BTESL students' perceptions of oral presentation anxiety. The outcome of this research is based on the numerical data obtained. A survey research methodology was utilized to collect data from respondents, examined through Statistical Package for the Social Sciences (SPSS). The adapted questionnaire would collect respondents' demographic information, their perceptions of anxiety in oral presentation and factors affecting oral presentations anxiety. 


\subsection{Sample}

The target population for this research is Management and Science University (MSU) students. The sampling was narrowed down to students taking Bachelor in Teaching English as a Second Language (BTESL), under the faculty of School of Education and Social Sciences (SESS). This study applied non-probability sampling, which is a nonrandom selection based on several criteria for data collection. Specifically, the chosen sampling method is convenience sampling under non-probability sampling. The researcher applied this type of sampling as BTESL students were the most accessible group of students as the researcher also studies in BTESL. Thus, the sample of this research is MSU BTESL students, regardless of age and gender. The estimation sample size is 273 with the confidence level of $95 \%$ and $5 \%$ margin of error.

\subsection{Instrument}

The research instrument of this study is a questionnaire. The questionnaire was adapted from an article that was related to the research topic. The published article was "Anxiety in classroom English Presentations: A Case Study in Korean Tertiary Educational Context" by (Tian, 2019), however, the researcher had adapted the questionnaire from FLCAS (Horwitz et al, 1986). The questionnaire consists of 22 items, 10 of it to measure respondents' perceptions of anxiety in classroom and 12 of it were to measure factors of classroom speaking anxiety, which were evaluated through a six-point Likert scale from "strongly disagree" to "strongly agree".

The questionnaire was then converted into Google Form for data collection. All the items were adapted from the above- mentioned article, but the researcher had added and changed several words to ensure it was aligned with the study's research objectives and research questions. The adapted questionnaire now consists of 3 questions to obtain respondents' demographic questions and 19 items to obtain respondents' perceptions of anxiety in oral presentation and factors affecting anxiety in oral presentation. The researcher also replaced the six-point Likert scale to a five-point Likert scale and removed several items. A fivepoint Likert scale measured all the items except for demographic questions.

\subsection{Pilot Study}

The researcher had distributed the questionnaire link to thirty (30) BTESL students through WhatsApp. Based on the pilot study's collected data, there were 21 items in the questionnaire that was distributed during the pilot study. The Cronbach's Alpha obtained for the pilot study was 0.902 . However, it was advised that the researcher reviewed the items to remove items that were similar to one another. Hence, the researcher had removed two items which were irrelevant and obtained Cronbach's Alpha of 0.885.

\subsection{Procedures and Data Analysis}

The collected quantitative data through a questionnaire regarding MSU BTESL students' perceptions towards anxiety in oral presentation and factors affecting anxiety in oral presentation served the purpose as primary data. The questionnaire which was developed using Google Form was distributed to the chosen respondents through WhatsApp academic groups and analyzed through SPSS. This software is used for statistical analysis to handle 
huge amounts of data (Durkheim, 1999). The researcher used descriptive statistics and mean scores to analyze the data.

\section{Results and Discussion}

\subsection{Demographic Information}

Table 1. The Demographic summary of the respondents $(\mathrm{N}=302)$

$\begin{array}{cccc} & \text { CHARACTERISTICS } & \text { Frequency, } \mathrm{n} & \text { Percentage, } \\ \text { Gender } & \text { Female } & 254 & \% \\ & \text { Male } & 48 & 84.1 \\ \text { Age } & & =302 & 15.9 \\ & 18-20 & 61 & 100 \\ & 21-23 & 206 & 20.2 \\ & 24-26 & 28 & 68.2 \\ & 27 \text { and above } & 7 & 9.3 \\ \text { Year of } & & 302 & 2.3 \\ \text { Study } & 1^{\text {st }} \text { Year } & 78 & 100 \\ 2^{\text {nd }} \text { Year } & 3^{\text {rd }} \text { Year } & 165 & 25.8 \\ & & =302 & 19.5 \\ & & 54.6\end{array}$

There are 254 female respondents and 48 male respondents. It can be seen that the female respondents outnumber male respondents, at $84.1 \%$ against $15.9 \%$, respectively. Majority of the respondents are female BTESL students. The total of respondents is $302(100 \%)$.

It shows 61 respondents in the range of age 18-20, 206 respondents in the range of age 21 23,28 respondents in the range of age 24-26, and 7 respondents in the range of age 27 years old and above. The largest percentage is in the range of 21-23 years old which is $68.2 \%$, followed by $18-20$ years old $20.2 \%, 24-26$ years old $9.3 \%$ and the lowest, age of 27 and above $2.3 \%$.

There are 78 first year BTESL students, 59 second year BTESL students and 165 third year BTESL students. The highest percentage of respondents are from third year students, $54.6 \%$, followed by $25.8 \%$ of first year students and the lowest, $19.5 \%$ of second year students. 


\subsection{Perceptions towards anxiety in oral presentation}

Table 2. Perceptions towards anxiety in oral presentation

No.

Item

Mean

2. I feel more tense and nervous about the oral presentation than other class activities.

3. I feel overwhelmed, because I have to learn the rules about how to give a good oral presentation.

5. I worry that I cannot make a good oral presentation.

8. I tremble when I know that I will be the next one to give the oral presentation.

9. It frightens me when I know the oral presentation will be graded by the teacher.

12. In the oral presentation, I may get so nervous that I forget what I know.

13. I can feel my heart pounding when I give the oral presentation.

17. I am usually at ease after finishing my oral presentation in the class.

18. After the oral presentation, I feel relaxed and happy when the teacher praises my performance.

Average

Mean

Table 2 presents the means of respondents on nine items about the perceptions of anxiety in oral presentation in the questionnaire. Based on Table 2, the highest mean is item 18 with 4.32 points. Furthermore, the lowest mean is item 3 with 3.35 points. The arrangement from highest to lowest mean are as follows; item 18 (4.32), item 17 (4.13), item 13 (3.82), item 5 (3.77), item 12 (3.70), item 8 (3.68), item 2 (3.62), item 9 (3.61) and item 3 (3.35). There are two items which are above 4.0, item 17 and item 18. Meanwhile, the other 7 items are above 3.0. Finally, the average mean for the 9 items is 3.78 . 


\subsection{Perceptions towards factors affecting anxiety in oral presentation}

Table 3. (A) Perceptions towards factors affecting anxiety in oral presentation

$$
\mathrm{N}
$$

o.

1 I feel self-confident about speaking English . in front of other students.

1 I keep thinking that the other students are

5. better at giving oral presentations in English than I am.

4 It worries me when I know I need to give multiple oral presentations in the class.

6 I made a full preparation for my oral presentation.

7 I start to panic when I give the oral presentation without enough preparation.

1 I'm afraid that my teachers tend to give

0 . negative feedbacks after my oral presentation.

1 I get upset when I don't understand the

9. teacher's specific feedback on my oral presentation.

1 I don't worry about making mistakes when I

1. give the oral presentation.

1 When giving oral presentation, I often stutter

4. or repeat words when the teacher and other classmates gaze at me.

1 I am afraid that the other students will laugh

6. at me when I give the oral presentation.
Factors

Category

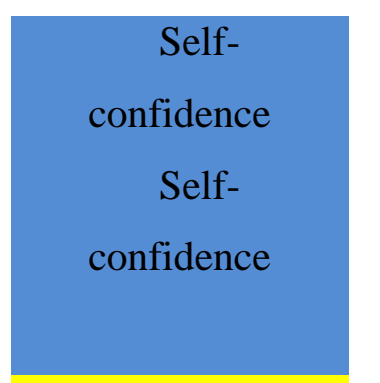

Number of

presentations

Preparation

Preparation

Feedback

Teacher's

Feedback

Make Mistakes

Audience's

Attention

Audience's

Attention

Average mean

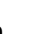

Mea

is


affecting anxiety in oral presentation; self-confidence, number of presentations, preparation, teacher's feedback, make mistakes and audience's attention. Based on Table 3 (A), the highest average score is item 7 with 3.95 points under the category factor of preparation and the lowest average score is item 11 with 2.83 point under the category factor of make mistakes. The arrangement from highest to lowest average score are as follows; item 7 (3.95), item 6 (3.90), item 15 (3.72), item 4 (3.67), item 10 (3.64), item 19 (3.60), item 1 (3.51), item 14 (3.50), item 16 (3.30) and item 11 (2.83). There is only one item in the range below 3.0, which is item 11 with score of 2.83 meanwhile other items are all in the range of above 3.0 and below 4.0. Finally, the mean of total average score for the ten items is 3.56. Figure 4.3.2 (A) below shows the visual representation of this research question.

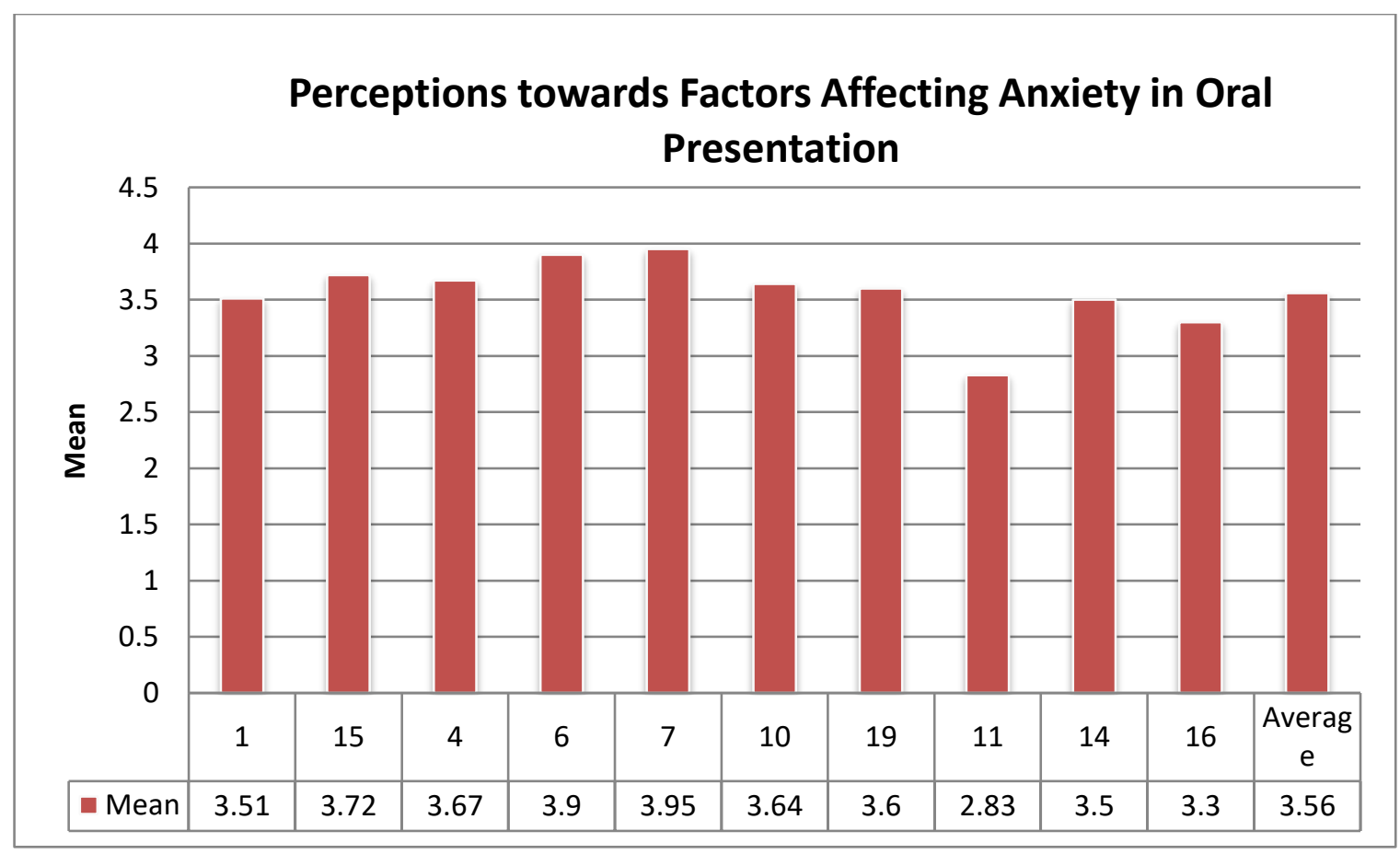

Figure 4.3.2 (A)

Table 4. (B) Average mean of perceptions towards factors affecting anxiety in oral presentation based on category of factors

No.

Item

Factors

Mean 
78 Mohammad A. Al-Saggaf \&, Amira Aida Iman binti Azman

1. I feel self-confident about speaking English in front of other students.

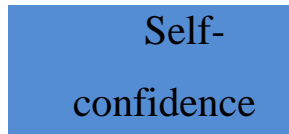

15. I keep thinking that the other students are better at giving oral presentations in English than I am.

6. I made a full preparation for my oral presentation.

7. I start to panic when I give the oral presentation without enough preparation.

10. I'm afraid that my teachers tend to give negative feedbacks after my oral presentation.

19. I get upset when I don't understand the teacher's specific feedback on my oral presentation.

14. When giving oral presentation, I often stutter or repeat words when the teacher and other classmates gaze at me.

16. I am afraid that the other students will laugh at me when I give the oral presentation.

4. It worries me when I know I need to give multiple oral presentations in the class.

11. I don't worry about making mistakes when I give the oral presentation.

Mistakes

Table 4 (B) presents the average mean of perceptions towards factors affecting anxiety in oral presentation based on category of factors. There are six factors affecting anxiety in oral presentation based on the items; self-confidence, number of presentations, preparation, teacher's feedback, make mistakes and audience's attention. Arrangement from highest to lowest mean are as follows; 3.93 (preparation), 3.67 (number of presentations), 3.62 (self-confidence), 3.62 (teacher's feedback), 3.40 (audience's attention) and 2.83 (make mistakes). The mean for factors 
of self-confidence and teacher's feedback are the same. Figue 4.3.2 (B) below shows the visual representation of this research question.

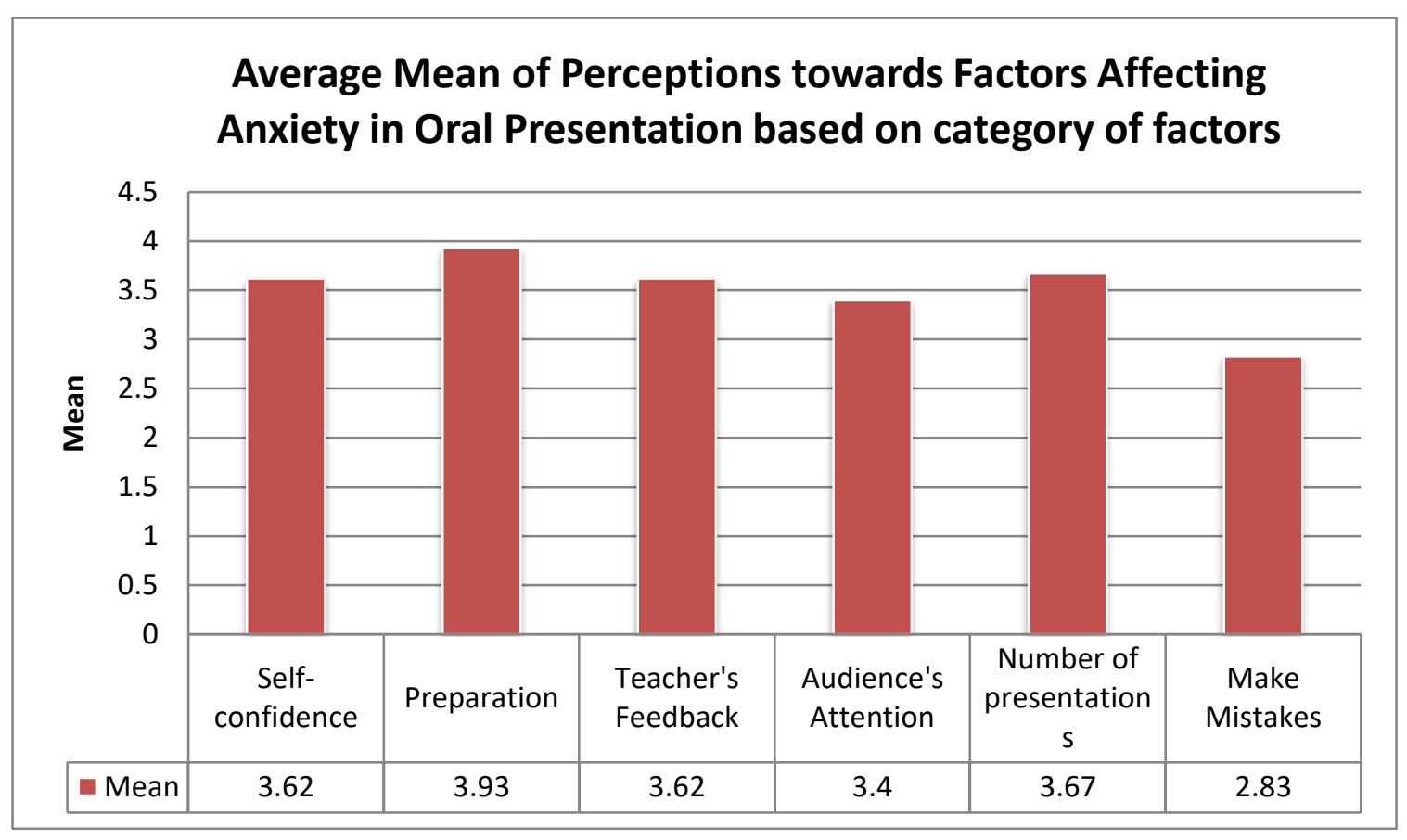

Figure 4.3.2(B)

Based on the results, it can be seen that BTESL students in Management and Science University perceived anxiety in oral presentation to be negative as most of the respondents agreed with the items in the questionnaire. The analysis of each item above had shown the respondents experience anxiety and nervousness regarding oral presentation. The respondents would also display both positive and negative manifestations of language anxiety such as increased motivation for presentation preparation. However, they would display negative anxiety behaviors such as trembling, accelerated heartbeat and forgetfulness. Previous researchers supported it, such as Choi (2016) who found that their participants perceived impromptu speaking activities would be anxiety-provoking but could be reduced through sufficient preparation. Furthermore, the second research question regarding MSU BTESL students' perceptions towards factors affecting anxiety in oral presentation revealed a total of six factors. The arrangements of major to minor factors were as follows; preparation, number of presentations, self-confidence, teacher's feedback, audience's attention, and make mistakes. All of these factors were similar to previous studies such as Fadlan (2020), Razawi, Zulkornain and Razlan (2019) and Tian (2019). 


\section{Conclusion}

This study was designed to investigate the perceptions towards anxiety in oral presentation and factors affecting anxiety in oral presentation among students of Bachelor in Teaching English as a Second Language in Management and Science University, Malaysia. The researcher analyzed the collected data from the questionnaire using Statistical Package for Social Sciences (SPSS) and obtained the frequency, mean and average mean of the items. The findings revealed that MSU BTESL students perceived anxiety in oral presentation to be negative, which is aligned with Young (1990) argument that students perceived the most anxious experience is speaking in a foreign language.

Moreover, another essential finding showed that MSU BTESL students perceived and experienced all six factors presented as items in the questionnaire adapted from a previous article entitled "Anxiety in classroom English Presentations: A Case Study in Korean Tertiary Educational Context" by (Tian, 2019). The factors obtained were; preparation, number of presentations, self-confidence, teacher's feedback, audience's attention, and make mistakes, in which among all of these factors, preparation was the most prominent one. Based on this study, it was suggested that even though there are numerous studies on speaking anxiety in oral presentation, Handayani, Rozimela and Fatimah (2020) conclude that students still experience the anxiety. Hence, this research topic is still a relevant and essential issue that requires effective solutions to ensure students' anxiety could be reduced, overcome, and not negatively impact their oral performance.

Based on the conclusion above, further research is required to accommodate various oral presentation anxiety variables such as the perceptions, anxiety level, factors affecting, and strategies to overcome the anxiety. It would provide more quality research if future researchers compare the perceptions between year of study, courses or faculties if the educational setting is in a tertiary context. Speaking anxiety is common as Torky (2006) mentions that the most frequent language skill used skill is speaking which is also supported by Rivers (1981) who identifies that speaking is rated double the usage than reading and writing in communication. Hence, more research should be conducted on anxiety in oral presentation.

\section{References}

[1] Alnahidh, Faye, and Sultan Altalhab. (2020). The Level and Sources of Foreign Language Speaking Anxiety among Saudi EFL University Students, Advances in Language and Literary Studies, 11.1, 55 https://doi.org/10.7575/aiac.alls.v.11n.1p.55

[2] Anwari, Ahmad (2019), 'Investigating the Causes and Negative Effects of English Language Speaking Anxiety: A Case Study among EFL Learners at Kandahar University', American International Journal of Education and Linguistics Research, 2.2, 10-21 <https://doi.org/10.46545/aijelr.v2i2.77>

[3] Banu, M A Sahna, and A.M.M Navas (2019). A Study on Language Anxiety Among The ESL a Study on Language Anxiety among The ESL Undergraduates at The South Eastern University Of Sri Lanka, 9th International Symposium (IntSym 2019), November, 910-22 retrieved from http://ir.lib.seu.ac.lk/handle/123456789/4120 
[4] Fadlan, Azwar (2020), 'Factors Causing Language Anxiety of EFL Students in Classroom Presentation', ELS Journal on Interdisciplinary Studies in Humanities, 3.2, 219-30 <https://doi.org/10.34050/els-jish.v3i2.9718>

[5] Ka-kan-dee, Maleerat, and Ghayth Kamel Shaker Al-Shaibani (2018). Tourism Students' Oral Presentation Anxiety: A Case Study, Pertanika Journal of Social Sciences and Humanities, 26.T, 231-56 Retrieved from https://www.researchgate.net/publication/330002940_Tourism_Students'_Oral_Presentation_Anx iety_A_Case_Study

[6] Khusnia, Aulia Nisa (2016). Students' Perspectives on Speaking Anxiety in the English Foreign Language Classroom, Ahmad Dahlan Journal of English Studies, 3.2, 41 <https://doi.org/10.26555/adjes.v3i2.4988>

[7] Miskam, Nuraqilah Nadjwa, and Aminabibi Saidalvi (2018), 'Investigating English Language Speaking Anxiety among Malaysian Undergraduate Learners', Asian Social Science, 15.1, 1 https://doi.org/10.5539/ass.v15n1p1

[8] Soomro, Muhammad Arif, Insaf Ali Siming, Syed Hyder Raza Shah, Mukhtiar Ali Rajper, Sadia Naz, and Mansoor Ahmed Channa (2019), 'An Investigation of Anxiety Factors During English Oral Presentation Skills of Engineering Undergraduates in Pakistan', International Journal of English Linguistics, 9.3, 203 <https://doi.org/10.5539/ijel.v9n3p203>

[9] Tian, Chunguang (2019). Anxiety in Classroom English Presentations: A Case Study in Korean Tertiary Educational Context, Higher Education Studies, 9.1, 132 <https://doi.org/10.5539/hes.v9n1p132>

[10] Tulgar, Ayşegül Takkaç (2018). Speaking Anxiety of Foreign Learners of Turkish In, International Online Journal of Education and Teaching (IOJET), 5(2), 313-32 Retrieved from http://iojet.org/index.php/IOJET/article/view/362/237

[11] Yassin, A. A., Razak, N. A., \& Maasum, N. R. M. (2019). Investigating the need for computer assisted cooperative learning to improve reading skills among Yemeni university EFL students: a needs analysis study. International Journal of Virtual and Personal Learning Environments (IJVPLE), 9(2), 15-31. 